\section{Estimating preventable hospital deaths: the authors reply}

We thank Dr James for offering further comments on the debate on estimating deaths due to medical error, and for his clarification of the definition used in his Journal of Patient Safety article. ${ }^{1}$ Dr James' letter reinforces the need for improved consistency, explicitness and reproducibility in measurement of medical error (and harms associated with it) that we called for in our article. ${ }^{2}$

One area where such clarity is much needed is in what Dr James describes as errors of omission, which by their nature are more difficult to detect than the slips and lapses that have traditionally been the concern of patient safety efforts. He mentions the example of $\beta$-blockers as a treatment for patients with heart failure, but this is not a straightforward example of deficient practice. While it is true that some early studies in the 1980s suggested a positive impact, $\beta$-blockers did not become widely recommended for heart failure until the 1990s because it continued to be an area of controversy until the evidence had become more firmly established. And, though $\beta$-blockers did go on to become standard treatment of heart failure, the much-touted use of perioperative $\beta$-blockers-which became a widely commended patient safety practice based on early trials-did not. In fact, perioperative $\beta$-blockers were associated with harm. ${ }^{3}$

These twists and turns in the evidence base are often the norm in healthcare. In consequence, while it may appear in hindsight that early studies should have changed practice, the results of early trials are often not replicated or they are even overturned in real time. ${ }^{45}$ One survival analysis found that an important change in a result or recommendation occurred for $57 \%$ of 100 systematic reviews (95\% CI $47 \%$ to $67 \%){ }^{6}$ median duration of survival free of a signal for updating was 5.5 years (CI 4.6 to 7.6 years). However, a signal occurred within 2 years for $23 \%$ of reviews and within 1 year for $15 \%$. In $7 \%$, a signal had already occurred at the time of publication.

A further challenge with identifying errors of omission is that it risks making any under-use of evidence-based therapy into a safety problem. Among other things, it runs into the definitional problem that identifying a time after which the failure to use some therapy should be regarded as an error is not easy, and may not adequately account for the role of patient preference or well-informed clinical judgement in choices about such therapies.

Not everyone will agree with these points. That is fine: legitimate disagreement is the hallmark of a healthy scientific field. What is not fine is allowing a failure to reach consensus to blight the field, and in particular to damage the endeavour of quantifying rates of avoidable harm. We fully support Dr James' call for development of a consensus definition.

\section{Kaveh G Shojania, ${ }^{1}$ Mary Dixon-Woods ${ }^{2}$ \\ ${ }^{1}$ Department of Medicine, University of Toronto, Toronto, Ontario, Canada \\ ${ }^{2}$ Primary Care Unit, University of Cambridge Institute of Public Health, Cambridge, UK}

Correspondence to Dr Kaveh G Shojania
Department of Medicine, University of Toronto, Sunnybrook Health Sciences Centre, 2075 Bayview Avenue, Rm H468, Toronto, Ontario M4N 3M5, Canada; kaveh.shojania@sunnybrook.ca

Competing interests None declared. Provenance and peer review

Commissioned; internally peer reviewed.

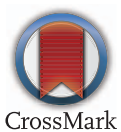

To cite Shojania KG, Dixon-Woods M. BMJ Qual Saf Published Online First: [please include Day Month Year] doi:10.1136/bmjqs-2016-006341

Received 5 January 2017

Accepted 10 January 2017

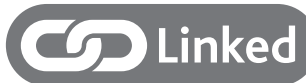

- http://dx.doi.org/10.1136/bmjqs-2016-006340

\section{REFERENCES}

1 James JT. A new, evidence-based estimate of patient harms associated with hospital care. J Patient Saf 2013;9:122-8.

2 Shojania K, Dixon-Woods M. Estimating deaths due to medical error: the ongoing controversy and why it matters. BMJ Qual Saf 2016; doi:10.1136/bmjqs-2016-006144. [Epub ahead of print].

3 Neuman MD, Bosk CL, Fleisher LA. Learning from mistakes in clinical practice guidelines: the case of perioperative beta-blockade. BMJ Qual Saf 2014;23:957-64.

4 Ioannidis JP. Contradicted and initially stronger effects in highly cited clinical research. JAMA 2005;294:218-28.

5 Ioannidis JP. Is it possible to recognize a major scientific discovery? JAMA 2015;314:1135-7.

6 Shojania KG, Sampson M, Ansari MT, et al. How quickly do systematic reviews go out of date? A survival analysis. Ann Intern Med 2007;147:224-33. 